neighbours, but adopted a description of their speciality which had an upbeat first and neutral second term (genito- and urinary, respectively). Sometimes this was cleverly reinforced by a move from poor premises outside the walls of hospitals to proper clinics within. Clear messages about the dangers of the conditions and their susceptibility to treatment was an issue, with informed guidance, for central and local health service organisations.

Some of those within psychiatry seem intent on the opposite path.

Is it possible that in psychiatry we have neglected the importance of symbolism, both to our patients and ourselves, in supporting the work we do? Sectorisation, 'community' trusts, the spectre of 'mental health' commissioning authorities, and professors of 'social' and 'community' psychiatry all stigmatise psychiatry as a 'different' medical speciality; we have much to do.

D. M. Bowker, Consultant Psychiatrist, Rochdale Healthcare NHS Trust, Birch Hill Hospital, Rochdale OL12 9QB

\section{Primary care-based mental health promotion drop-in clinic}

Sir: It is difficult to agree with the conclusions of Gilleard \& Lobo (Psychiatric Bulletin, September $1998,22,559-562)$ that "there is a viable role for mental health promotion" in the form of a drop-in clinic based in primary care. Only 55 contacts occurred in 11 months at a twice weekly clinic run by two members of the mental health team. This represents around one patient seen for every 10 hours of professional time, which seems a rather expensive way of distributing information leaflets while informing patients and surgery staff about relevant local non-NHS services. Most general practitioners would consider that a poster in the waiting room would achieve a similar objective and capture a much wider audience at a fraction of the cost.

Paul BlenkIRon, Specialist Registrar in Psychiatry, Department of Liaison Psychiatry. Clinical Sciences Building, St James' University Hospital, Beckett Street, Leeds LS9 7TF

\section{Medical reports for mental health review tribunals}

Sir: Ismail et al (Psychiatric Bulletin, October 1998, 22, 615-618) found at the Maudsley Hospital that three-quarters of Section 3 tribunal reports studied had failed to address completely the statutory criteria for continuing detention, without that failure having affected the outcome of hearings. They advocate replication of their study elsewhere and better training for report writing.

The roles of doctors in mental health review tribunals have been surveyed by Langley (1990) and Woolf (1991). It will always be an essential routine at tribunal hearings to address the statutory criteria orally during the questioning of the doctor who attends to represent the health authority. This is required to establish whether the conclusions of the report need to be amended on the day of the hearing, even for the minority of Section 3 cases in which medical reports are 'complete'.

Of far greater concern for tribunal members, patients' representatives and their independent experts, and for Mental Health Act administrators, is the equally common failure of responsible medical officers to deliver Section 3 reports within the prescribed three weeks (over $70 \%$ at some hospitals).

There may be several good reasons why this happens, including wide misunderstanding of the requirement and its importance. Delays are often justified on the basis that the patient's mental state might change and that it remains to be decided whether the further detention will ultimately be defended. Woolf (1998) has discussed hearings abandoned, often very late and, sometimes inexplicably, without medical reports having been submitted. Early, concise reports, focused upon the key issues, and later supplemented by updates as necessary, make for smoother and better tribunal hearings.

LANGLEY, G. E. (1990) The RMO and mental health review tribunals. Psychiatric Bulletin. 14, 336-337.

Woolf. P. G. (1988) Abortive hearings. MHRT Members News Sheet, 2. 8.

- (1991) The role of the doctor in the mental health review tribunal. Psychiatric Bulletin. 15. 407-409.

P. G. Woolf, Consultant Psychiatrist and Medical Member of MHRT 1966-98, 2a Vanbrugh Hill, London SE3 TUF

\section{Use of placebo}

Sir: There are only a few articles published on the use of placebo, either for diagnostic or treatment purposes; one notable and helpful example being Miller (1988).

I tend to use placebo sometimes for diagnostic purposes but more often as an adjunct in the treatment of anxiety, mild depression and insomnia. Except in one case its use was limited to oral 'medication'. My use of placebo was hotly challenged by visiting commissioners who considered it unlawful. After recent correspondence, the Chief Executive of the Mental Health Act Commission replied following discussion with 